\title{
Maintaining a Rewarding Biomedical Engineering Capstone Experience for Students in Remote Learning Situations
}

\author{
J. A. LaMack, I. dos Santos, and O. Imas \\ Electrical Engineering and Computer Science Department, Milwaukee School of Engineering, Milwaukee, WI, USA
}

(Received 1 July 2020; accepted 10 August 2020; published online 20 August 2020)

\section{CHALLENGE STATEMENT}

A sudden, mandated transition to virtual learning presents innumerable challenges to students and instructors in an engineering capstone design course. Depending on the timing of the transition, as well as the nature of the project, it may become impossible for students to endeavor to build and test a prototype for their design. While some barriers may prove insurmountable under circumstances that involve mandatory quarantine practices, there may be opportunity for faculty to influence students' motivation in capstone design courses.

Different dimensions of motivation can influence student performance in such courses. Implementing dimensions of student motivation adapted from Pintrich $^{1}$, Kames et al. found that in a mechanical engineering capstone design sequence, the importance of intrinsic motivating factors (such as recognition of the value of a task and benefit of its completion) is most related to student performance at the beginning of the project. ${ }^{2}$ While intrinsic motivation is still a factor later in the project, other motivational dimensions, in particular, cognitive value (representing possession and implementation of necessary competencies to complete a task) and residency (here, distinguishing domestic from international students), become more important. Furthermore, students whose performance decreased from beginning to end of the capstone sequence experienced possible decreases in motivation through intrinsic factors.

Our faculty recognized that all three dimensions of student motivation reported to be relevant toward the end of a capstone design experience, ${ }^{2}$ as well as

Address correspondence to J. A. LaMack, Electrical Engineering and Computer Science Department, Milwaukee School of Engineering, Milwaukee, WI, USA. Electronic mail: lamack@msoe.edu extrinsic motivation factors addressing reward and recognition, ${ }^{1}$ could be adversely impacted by a virtual learning environment. Cognitive motivation could suffer if students did not have the resources to complete and test their design prototypes. Intrinsic motivation could be affected by the absence of an ability to envision benefits of meeting design requirements. Extrinsic motivation includes recognition for achievements and rewards. Issues with extrinsic motivation, particularly for higher performing students, could be exacerbated by widely adopted temporary grading scales (i.e., pass/fail) that do not distinguish between passing levels of performance. Finally, while the ratio of domestic and international students was not directly impacted, residency encompasses not only language and cultural factors, but also social integration, the latter of which would likely be impacted when students cannot physically interact.

Therefore, the challenge we sought to address was how to maintain a critical level of different dimensions of motivation to drive students to maximize their efforts throughout the entire final academic term of biomedical engineering capstone design in the face of barriers associated with remote learning and less rewarding grading scales.

\section{NOVEL INITIATIVE}

To address the challenge, our faculty instituted some unique approaches and benefitted from other approaches that were already in place that we believe would positively impact the different dimensions of motivation of senior biomedical engineering students in their final capstone design course. These approaches and the motivational dimensions that they address are summarized in Table 1. 
TABLE 1. Summary of motivational dimensions (adapted from References 1 and 2) and the approaches used to address each dimension with respect to challenges of a virtual learning environment in a final capstone design course.

Motivational dimension

Related course approaches

Cognitive

Systems approach: subsystems allowing individual students to implement competencies Analysis of simulated test data

Intrinsic

Systems approach: system/subsystem dependencies and comprehensive risk assessment Greater emphasis on test plan

Extrinsic

Residency/Social Integration

Public virtual final design events

Virtual communication tools

Our program's capstone sequence is set up as a series of four courses in a quarter-based academic curriculum. The first course is taken in the spring quarter of the junior year. The goal of this course is to create teams, assign projects, and allow teams to gain an in depth understanding of the problem to which they are assigned to solve by identifying design inputs based on user needs and other constraints (regulatory, economics-driven, etc.). At the beginning of the senior year, teams are ready to begin developing design concepts.

We have traditionally employed a systems engineering approach in our capstone design courses. Teams are required to decompose their system into discrete subsystems, with one or two students responsible for the design of each subsystem. The entire design process, including identification of requirements, consideration of alternative solutions, building/testing, and evaluation, are required for each subsystem. ${ }^{3}$ Once subsystems are complete, teams generally connect them and proceed with system-level testing. While the systems approach was already being used in our courses, in the virtual environment in which students and their respective subsystems were isolated from each other, we placed greater emphasis on risk assessment that involved identification of potential hazards in each subsystem. In addition, students were required to conduct thorough definition of interface specifications. They were guided to explicitly set measurable inputs and outputs of their subsystems and to compare those needs with off-the-shelf transducers, microcontrollers, and other parts. Putting these strategies in place would allow students to realize the feasibility of their designs, taking into consideration not only the availability of parts on the market but also their cost. This would maximize the likelihood that the entire system would meet requirements, even if students were physically unable to connect their subsystems and conduct system-level testing.

The ability of individual students to complete all design tasks for their respective subsystems does depend on the availability of resources to build and test their subsystems. While building and testing of some types of subsystems (software, those involving handheld electronics, etc.) is realistic for students to complete remotely, it is not realistic for other types of subsystems. For cases in which barriers prevented students from physically building and testing prototypes, faculty advisors worked with individual students, as well as teams, to develop final milestones that involved more thorough and numerous test plans than we normally require. In some cases, students were encouraged to create sample data and perform statistical analysis to demonstrate an ability to evaluate success of meeting a design requirement. Taken together, the systems approach and the alternative emphasis on test plan development addressed the cognitive and intrinsic motivation dimensions, as they made achievement of a concrete goal within reach of most students despite physical separation from university resources and from each other.

While rewards systems such as grades may be of limited influence in motivating engineering capstone design students, ${ }^{4}$ it is unclear whether removing this reward system by reducing the grading scale to a pass/ no pass variant can demotivate students in capstone classes, particularly when other rewards are removed. Capstone engineering design students are typically rewarded through recognition of their achievements at formal capstone showcases or presentations, often open to the public. In a remote learning situation, such public events are prohibited, removing another level of reward for students.

To counteract potential losses in extrinsic motivation, our faculty planned and publicized virtual final design events for each team to replace our design showcase and senior design presentations that are normally scheduled the day before our spring commencement ceremony. The virtual final design event for each of our nine design teams was scheduled for one hour during the final two weeks of classes. The first thirty minutes of each event, conducted using Microsoft Teams, was open to the public. Students were encouraged to invite friends and family, and organizers also extended invitations to other students, faculty, and alumni. This session consisted of a formal pre- 
sentation followed by a period for questions and answers. The session was recorded, and the link to the recording was given to students to share with others. For the second thirty-minute session, only design team students, program faculty, and members of the program's industrial advisory board were allowed to participate. This session was conducted as a final design review in which faculty and industry members asked the team technical questions related to their design approach, test plans, and final evaluations.

\section{REFLECTION}

Anecdotally, participation in the virtual final design events was substantial, and faculty felt that, not only were final presentations of high quality, but overall success of design teams in meeting their respective design requirements was comparable to prior years of traditional in-person instruction. We believe this was achieved through efforts to maintain cognitive, intrinsic, and extrinsic motivation that impacts student learning and performance ${ }^{1,2}$ and by providing a means for rewarding design students through public recognition of their efforts and achievements. While the overall systems engineering approach was not new, it proved valuable in providing discrete, achievable projects for individual students, particularly with added emphasis on interface requirements, risk assessment, and creation of thorough test plans at the subsystem level.

Faculty felt that public recognition as a reward was particularly important as an extrinsic motivational factor in light of the altered grading system adopted by our university. Our students were not given the option to choose a traditional discriminating grading scale. Well-planned pass/fail grading schemes have been used successfully to reduce competition and enhance motivation through self-regulated learning. ${ }^{5}$ However, as pass/fail schemes were being adopted by many universities in the 1960s and 1970s, there was evidence that such a scheme could negatively impact student performance. ${ }^{6}$

Most implementations of pass/fail grading schemes adopted by universities during obligatory virtual learning were done out of concerns about the accuracy of traditional grades in reflecting student knowledge in an educational environment that was new to both students and teachers. As such, courses were generally not designed to take advantage of potential benefits of such a system, ${ }^{5}$ so one would not necessarily expect motivational benefits of a pass/fail grading system under such circumstances. Additionally, in a capstone design course, grade may reflect quality and complexity of student work more than it does in other courses, making discriminating grading scales more important. Anecdotally, several of our students expressed concern that the pass/fail grading scheme would not reward them for their efforts in their design course. In contrast, previous work indicates a lesser relative importance of grades as a motivational factor in capstone design. ${ }^{4}$ The effects of obligatory, as well as optional, pass/fail grading systems on student motivation and performance in different types of courses merits further investigation.

While not all limitations associated with reduced access to resources could be overcome, faculty felt that most students had a concrete and achievable final deliverable. One motivational factor that could not be completely overcome was that of social integration, an element of the residency motivation dimension. Students were encouraged to maintain communications amongst themselves as much as possible using collaborative tools such as Microsoft OneNote and Microsoft Teams, and they proved effective at using these tools that are of increasing importance in industry. However, the regret that students most reported to faculty throughout the academic term was the inability to work with classmates to physically build and test their designs. While team camaraderie was evident at the virtual final design events, the faculty feel improvements can be made to enhance social interactions of students, should the need to conduct virtual instruction of capstone design arise again in the future.

Due to its unexpected need for implementation during the COVID-19 pandemic, faculty made no effort to formally evaluate the impact of the changes to the final capstone design course in a virtual learning environment through data collection. It would not be practical, nor likely possible, to create a control situation for this study in which virtual learning were necessitated in only the final capstone design course, health concerns prevented face-to-face teamwork, and the efforts described in this work were not instituted. However, it may be possible to assess impacts of certain approaches individually. The Motivated Strategies for Learning Questionnaire (MSLQ) is a validated survey to quantify levels of different dimensions of motivation of students. ${ }^{1}$ Such a tool could be used to investigate correlations between different educational approaches and motivation. Combined with faculty evaluations, these factors could then be related to student performance. Examples of factors that could be systematically varied among student teams include level of project decomposition and requirements of test plans, risk assessment, and definition of interface specifications. However, variability from confounding factors, such as project complexity, student abilities, and personal impacts of the pandemic, would likely 
obscure effects from the factors addressed in this work, thus necessitating some reliance on anecdotal evidence.

The faculty plan to continue the format of our program's capstone design courses, including the requirement of a systems engineering approach, regardless of the format of instruction in the future, as the benefits apply universally. We found the alternate deliverable of more elaborate test plans an effective option when the ability of students to build and test was compromised. Finally, due to its high participation rate and the high demand from students for access to their recordings, the program is considering continuing elements of the virtual final design event, even when in-person instruction and public gatherings are allowed. Overall, several useful insights were gained from the unexpected circumstances arising from the COVID-19 pandemic.

\section{ACKNOWLEDGMENTS}

The authors kindly thank Paul Licato for his work as an instructor in the design course described in this study and his participation in implementing the ideas described.

\section{CONFLICT OF INTEREST}

Not applicable.

\section{ETHICAL APPROVAL}

Not applicable.

\section{CONSENT TO PARTICIPATE}

Not applicable.

\section{CONSENT FOR PUBLICATION}

Not applicable.

\section{AUTHOR CONTRIBUTIONS}

Conceptualizaton [JAL, IDS, OI]; implementation [JAL, IDS, OI]; writing - original draft preparation [JAL]; writing - review and editing [OI, IDS].

\section{FUNDING}

Not applicable.

\section{REFERENCES}

${ }^{1}$ Pintrich PR, DeGroot EV. Motivational and self-regulated learning components of classroom academic performance. J Educ Psychol. 1990;82(1):33-40.

${ }^{2}$ Kames E, Shah D, Clark MC, Morkos B. A mixed methods analysis of motivation factors in senior capstone design courses. ASEE Annual Conference and Exposition Conference Proceedings. 2019.

${ }^{3}$ Ogrodnik P. Medical device design: Innovation from concept to market. Oxford: Academic Press; 2012.

${ }^{4}$ Marin JA, Armstrong JE, Kays JL. Elements of an optimal capstone design experience. J Eng Educ. 1999;88(1):19-22.

${ }^{5}$ White CB, Fantone JC. Pass-fail grading: laying the foundation for self-regulated learning. Adv Health Sci Educ Theory Pract. 2010;15:469-77.

${ }^{6}$ Gold RM, Reilly A, Silberman R, Lehr R. Academic achievement declines under pass-fail grading. J Exp Educ. 1971;39(3):17-21. 